\title{
Financial burden and impact of atopic dermatitis out-of-pocket healthcare expenses among black individuals in the United States
}

\author{
Raj Chovatiya $^{1}$ (1) $\cdot$ Wendy Smith Begolka² $\cdot$ Isabelle J. Thibau ${ }^{2} \cdot$ Jonathan I. Silverberg $^{3}$ (i)
}

Received: 13 May 2021 / Revised: 13 May 2021 / Accepted: 16 September 2021 / Published online: 27 September 2021

(c) The Author(s) 2021

\begin{abstract}
Black race is associated with increased atopic dermatitis (AD) severity and healthcare resource utilization. However, the burden of out-of-pocket (OOP) expenses among black individuals with $\mathrm{AD}$ is not well understood. We sought to characterize the categories and impact of OOP healthcare expenses associated with AD management among black individuals. A 25-question voluntary online survey was administered to National Eczema Association members $(N=113,502)$. Inclusion criteria (US residents age $\geq 18$ years; self-report of $\mathrm{AD}$ or primary caregivers of individuals with $\mathrm{AD}$ ) was met by $77.3 \%$ (1118/1447) of respondents. Black individuals with $\mathrm{AD}$ were younger, had lower household income, Medicaid, urban residence, poor AD control and frequent skin infections $(P \leq 0.02)$. Blacks vs. non-blacks reported more OOP costs for prescription medications covered $(74.2 \%$ vs. $63.6 \%, P=0.04)$ and not covered $(65.1 \%$ vs. $46.5 \%, P=0.0004)$ by insurance, emergency room visits $(22.1 \%$ vs. $11.8 \%, P=0.005)$, and outpatient laboratory testing $(33.3 \%$ vs. $21.8 \%, P=0.01)$. Black race was associated with increased household financial impact from OOP expenses $(P=0.0009)$, and predictors of financial impact included minimally controlled AD (adjusted OR [95\% CI] 13.88 [1.63-117.96], $P=0.02$ ), systemic therapy $(4.34$ [1.63-11.54], 0.003), $>\$ 200$ monthly OOP expenses (14.28 [3.42-59.60], $P=0.0003)$, and Medicaid (4.02 [1.15-14.07], $P=0.03)$. Blacks with Medicaid had higher odds of harmful financial impact (3.32 [1.77-6.24], $P=0.0002)$ than those of black race (1.81 [1.04-3.15], $P=0.04)$ or with Medicaid (1.39 [1.02-1.88], $P=0.04)$ alone. Black race is associated with increased OOP costs for AD and significant household financial impact. Targeted interventions are needed to address financial disparities in AD.
\end{abstract}

Keywords Atopic dermatitis $\cdot$ Out-of-pocket $\cdot$ Expense $\cdot$ Cost of care $\cdot$ Financial burden

R. Chovatiya and W. Smith Begolka contributed to this work equally.

Wendy Smith Begolka

wendy@ nationaleczema.org

Raj Chovatiya

raj.chovatiya@gmail.com

Isabelle J. Thibau

isabelle@nationaleczema.org

Jonathan I. Silverberg

jonathanisilverberg@gmail.com

1 Department of Dermatology, Northwestern University Feinberg School of Medicine, Chicago, IL 60611, USA

2 National Eczema Association, 505 San Marin Dr \#B300, Novato, CA 94945, USA

3 Department of Dermatology, The George Washington University School of Medicine and Health Sciences, Washington, DC 20037, USA

$\begin{array}{ll}\text { Abbreviations } \\ \text { AD } & \text { Atopic dermatitis } \\ \text { OOP } & \text { Out-of-pocket } \\ \text { OTC } & \text { Over the counter } \\ \text { HRQoL } & \text { Health-related quality of life } \\ \text { HCP } & \text { Healthcare provider }\end{array}$

\section{Introduction}

Atopic dermatitis (AD) is one of the most common chronic inflammatory skin diseases among both United States (US) children and adults. Previous studies found the US prevalence of $\mathrm{AD}$ to be $7 \%$ in adults and $13 \%$ in children [1-3] $\mathrm{AD}$ is characterized by heterogenous skin lesions with varying distribution [4], a constellation of symptoms including itch, skin-pain [5], and mental health disturbances [6], numerous atopic and non-atopic comorbid health conditions $[7,8]$, and complex course consisting of variable persistence, flares, and severity $[9,10]$. Significant morbidity associated 
with AD contributes to reduced health-related quality of life (HRQoL) and immense psychosocial burden [1, 11, 12].

Clinical phenotype and patient-burden of AD vary across racial and ethnic groups [13]. This heterogeneity is likely driven by a complex interplay of intrinsic (e.g., genetics, skin barrier dysfunction, cutaneous immune skewing, comorbidities) and extrinsic (e.g., socioeconomic status, geographic location, environment/climate) factors [13-15]. Black individuals have a higher prevalence of $\mathrm{AD}$ [16-18], higher burden of moderate-to-severe disease [19], increased rates of allergic comorbidities [20], greater AD-related impact on HRQoL [21], and often present with more treatmentresistant disease [15]. These features can make long-term $\mathrm{AD}$ control quite difficult. Given variable long-term efficacy and safety of many current treatments, healthcare providers (HCPs) and patients frequently have to combine therapies, seek new treatments, and consider adjunctive approaches to achieve optimal results-all of which contribute increased costs.

Atopic dermatitis (AD) is associated with a considerable financial burden, consisting of elevated direct costs related to healthcare resource utilization and indirect societal costs secondary to lost work productivity [22-27]. From the perspective of individual households, out-of-pocket (OOP) expenses are an essential and tangible element in routine management of finances. Previous population-based studies showed multifactorial increases in overall OOP expenses in $\mathrm{AD}$ patients $[28,29]$, and more recently, it was shown that individuals with $\mathrm{AD}$ report a wide variety of distinct medical and non-medical OOP healthcare costs related to AD care [30]. While black race was shown to be associated with increased healthcare resource utilization in AD [26], little is known about OOP healthcare expenses related to management of $\mathrm{AD}$ care among black individuals. We hypothesized that black race is associated with unique categories of OOP healthcare expenses and increased household financial impact. In this study, we sought to characterize OOP costs and financial impact in black individuals with AD.

\section{Methods}

\section{Study design}

A 25-question voluntary survey was administered online to all National Eczema Association (NEA) members ( $>110,000$ individuals with $\mathrm{AD}$ and family members) between November-December 2019. Electronic informed consent was obtained, and respondents completing the survey were given the option to enter a drawing to win one of ten $\$ 50$ gift cards. Survey response was not linked to gift card drawing or distribution. Inclusion criteria included US residency, age $\geq 18$ years, and either self-report or primary caregiver of children or young adult with AD. The survey was started by 1447 persons, and 1118 (77.3\%) met inclusion criteria.

\section{Survey questions}

Diagnosis of AD was determined by yes/no response to "Have [you/the person with atopic dermatitis] been diagnosed with atopic dermatitis by a healthcare provider?" Demographics were collected, including age, gender, race/ethnicity, household income, insurance status, and geographical setting. Current $\mathrm{AD}$ severity (clear/mild/moderate/severe), control (very well/moderately well/somewhat/minimally/not controlled), number of flare days in the last month $(0 / 1-3 / 4-7 / 8-10 / \geq 11)$, number of HCP visits in the past year $(0 / 1 / 2 / 3 / 4 / 5 / \geq 6)$, HCPdiagnosed comorbid health conditions (asthma/allergic rhinitis/food allergy/frequent and/or persistent skin infections/ anxiety and/or depression), total number of prescriptions in the past year $(0 / 1 / 2 / 3 / 4 / 5 / \geq 6$, and specific topical (antimicrobials/corticosteroids/crisaborole/tacrolimus/pimecrolimus) and systemic (phototherapy/dupilumab/azathioprine/cyclosporine / methotrexate /mycophenolate mofetil/tacrolimus/oral corticosteroids/injectable corticosteroids) prescription therapies were also queried.

Respondents were also asked about: OOP expenses related to evaluation or treatment of $\mathrm{AD}$ in the past 30 days for current medical approaches; total yearly OOP expenses for $\mathrm{AD}$; and impact of yearly OOP expenses on household finances (none/minimal/moderate/significant/devastating).

\section{Data analysis}

Statistical analysis was performed using SAS version 9.4 (SAS Institute, Cary, NC). Chi-squared tests were used for comparisons of categorical variables including sociodemographics factors, AD severity and control measures, and categories of OOP expenses. Kruskal-Wallis one-way analysis of variance was used for comparison of median annual OOP costs. Predictors of financial impact were determined by multivariable logistic regression with invoked backward elimination stepwise selection with financial impact as the dependent variable. Two-way interactions of race and insurance on financial impact were assessed using bivariable and multivariable logic regression and included in models if significant $(P<0.05)$ and they modified effect size by $\geq 20 \%$. Corrected $P$ values $\leq 0.05$ were considered significant. 


\section{Results}

\section{Respondent characteristics and disease burden}

Overall, respondents included adults with $\mathrm{AD}$ (\% prevalence [frequency]: $77.5 \%$ [866]) and parents and/or primary caregivers of children, teens, or young adults with $\mathrm{AD}(22.5 \%$ [252]). Most respondents were white (72.4\% [697]), followed by black/African-American (10.6\% [102]), multiracial (6.5\% [63]), Asian (6.0\% [58]), other (2.9\% [28]), American Indian/Alaskan Native (0.8\% [8]), and Native Hawaiian/ Pacific-Islander (0.7\% [7]). Black vs. non-black individuals with $\mathrm{AD}$ were more likely to be younger ( $\leq 35$ years: $55.9 \%$ vs. $42.7 \%, P=0.001)$, non-Hispanic $(97.1 \%$ vs. $89.7 \%$, $P=0.02)$, have lower household income ( $\leq \$ 24,999: 31.7 \%$ vs. $16.8 \%, P=0.005)$, Medicaid or state assistance $(20.8 \%$ vs. $8.4 \%, P=0.0002)$, and live in an urban setting $(41.2 \%$ vs. $21.8 \%, P<0.0001$ ) (Table S1). Black vs. non-black respondents also had poorer disease control (minimally or somewhat controlled: $63.8 \%$ vs. $50.3 \%, P=0.02$ ), increased rates of frequent/persistent skin infections ( $28.4 \%$ vs. $18.1 \%$,
$P=0.01$ ), and lower rates of anxiety and/or depression ( $24.5 \%$ vs. $38.0 \%, P=0.008$ ).

\section{OOP expenses}

Black vs. non-black respondents were more likely to report OOP expenses for prescription medication co-pays covered by insurance $(74.2 \%$ vs. $63.6 \%, P=0.04)$, emergency room visits ( $22.1 \%$ vs. $11.8 \%, P=0.005)$, prescription medications not covered by insurance $(65.1 \%$ vs. $46.5 \%, P=0.0004)$, and outpatient laboratory testing ( $33.3 \%$ vs. $21.8 \%, P=0.01)$ (Table 1). Numerically higher proportions of black respondents also reported OOP expenses for co-pays and/or deductibles for doctor or other HCP office visits, hospitalization, anti-itch medications, pain medications, sleep medications, hygiene products, childcare, and transportation.

Given the significant proportion of black respondents reporting use of Medicaid, OOP costs were further stratified by insurance status. Fewer black individuals with vs. without Medicaid insurance reported OOP costs for deductibles for HCP office visits ( $50.0 \%$ vs. $76.9 \%)$, hospitalization ( $0 \%$ vs. $5.5 \%$ ), prescription medication co-pays covered by insurance ( $47.6 \%$ vs. $82.7 \%$ ), prescription medications not covered by
Table 1 Categories of OOP expenses stratified by black race

\begin{tabular}{|c|c|c|c|c|}
\hline \multirow[t]{2}{*}{ Variable } & \multirow[t]{2}{*}{ Overall $(n=1018)$} & \multicolumn{3}{|l|}{ Black race } \\
\hline & & No $(n=861)$ & Yes $(n=102)$ & $P$ value \\
\hline \multicolumn{5}{|l|}{ Healthcare providers and prescriptions } \\
\hline Deductible & $686(68.7 \%)$ & $575(68.3 \%)$ & $70(70.7 \%)$ & 0.62 \\
\hline Hospitalization & $23(2.5 \%)$ & $17(2.2 \%)$ & $4(4.3 \%)$ & 0.22 \\
\hline Prescriptions covered & $635(64.3 \%)$ & $530(63.6 \%)$ & $72(74.2 \%)$ & 0.04 \\
\hline Emergency room visits & $123(13.3 \%)$ & $92(11.8 \%)$ & $21(22.1 \%)$ & 0.005 \\
\hline Prescriptions not covered & $468(48.6 \%)$ & $377(46.5 \%)$ & $64(65.1 \%)$ & 0.0004 \\
\hline Lab testing & $216(23.2 \%)$ & $171(21.8 \%)$ & $31(33.3 \%)$ & 0.01 \\
\hline Outpatient phototherapy & $42(4.6 \%)$ & $34(4.4 \%)$ & $4(4.4 \%)$ & 0.99 \\
\hline Mental health services & $133(14.4 \%)$ & $111(14.3 \%)$ & $12(12.8 \%)$ & 0.68 \\
\hline \multicolumn{5}{|l|}{ Non-prescription health products } \\
\hline Moisturizers & $934(94.3 \%)$ & $800(94.2 \%)$ & $94(94.0 \%)$ & 0.93 \\
\hline Anti-itch meds & $647(68.3 \%)$ & $542(66.8 \%)$ & $73(75.3 \%)$ & 0.09 \\
\hline Allergy meds & $715(75.1 \%)$ & $609(75.0 \%)$ & $70(70.7 \%)$ & 0.35 \\
\hline Pain meds & $449(49.3 \%)$ & $376(48.4 \%)$ & $49(51.6 \%)$ & 0.56 \\
\hline Sleep meds & $336(37.0 \%)$ & $283(36.4 \%)$ & $37(39.8 \%)$ & 0.52 \\
\hline Bandages & $446(48.4 \%)$ & $400(50.8 \%)$ & $27(28.4 \%)$ & $<0.0001$ \\
\hline Hygiene products & $824(85.0 \%)$ & $703(84.6 \%)$ & $89(89.0 \%)$ & 0.24 \\
\hline Supplements & $491(52.2 \%)$ & $428(53.2 \%)$ & $43(44.3 \%)$ & 0.10 \\
\hline \multicolumn{5}{|c|}{ Complementary approaches and care coordination } \\
\hline Alternative therapy & $180(19.0 \%)$ & $157(19.2 \%)$ & $18(18.2 \%)$ & 0.80 \\
\hline Childcare & $48(5.2 \%)$ & $40(5.2 \%)$ & $6(6.5 \%)$ & 0.60 \\
\hline Adjunctive therapy & $150(15.9 \%)$ & $135(16.6 \%)$ & $10(10.2 \%)$ & 0.10 \\
\hline Specialized cleaning products & $732(74.7 \%)$ & $635(75.1 \%)$ & $74(73.3 \%)$ & 0.69 \\
\hline Specialized clothing and bedding & $430(44.8 \%)$ & $372(45.0 \%)$ & $42(42.4 \%)$ & 0.63 \\
\hline Transportation & $444(46.8 \%)$ & $370(46.4 \%)$ & $52(54.2 \%)$ & 0.15 \\
\hline
\end{tabular}


insurance (50.0\% vs. $70.1 \%$ ), and lab testing (25.0\% vs. $36.1 \%$ ) (Fig. 1A). Similar findings were seen in a number of other categories of non-prescription health products and complementary approaches and care coordination including (Fig. 1B, C).

A numerically higher proportion of black respondents reported use of step-up therapy (i.e., systemic therapy including injectable, oral, or phototherapy), prescription polypharmacy ( $\geq 3$ prescriptions), and higher monthly OOP costs for co-pays and/or deductibles for HCP office visits (Table 2). In contrast, respondents with Medicaid insurance reported significantly lower monthly OOP expenses in the same category and a numerically lower median OOP yearly cost. Black respondents with vs. without Medicaid insurance had a lower frequency of step-up therapy, higher rate of polypharmacy, and lower OOP monthly and yearly costs (Fig. 2A).

\section{Impact of OOP expenses}

Black race was associated with more harmful impact of OOP expenses for $\mathrm{AD}$ on personal/family finances $(P=0.0009)$ (Table 2). More black vs. non-black individuals with AD reported moderate $(44.1 \%$ vs. $39.5 \%)$, severe $(27.5 \%$ vs. $20.1 \%$ ), and devastating (3.9\% vs. $3.6 \%$ ) household financial impact. Medicaid vs. non-Medicaid insurance was similarly associated with a higher degree of moderate $(51.6 \%$ vs. $38.7 \%$ ), severe ( $21.5 \%$ vs. $21.1 \%$ ), and devastating ( $7.5 \%$ vs. $3.3 \%)$ household financial impact $(P=0.005)$. A numerically higher proportion of black respondents with vs. without Medicaid insurance reported severe or devastating financial impact (Fig. 2B).

Positive predictors of harmful financial impact among blacks with AD included minimally controlled AD (adjusted odds ratio [95\% confidence interval], $\mathrm{P}$ value: 13.88 [1.63-117.96], $P=0.02$ ), comorbid anxiety and/or depression (4.34 [1.37-13.70], $P=0.01)$, step-up therapy (4.34 [1.63-11.54], 0.003), > \$200 spent on monthly OOP expenses for co-pays and/or deductibles for $\mathrm{HCP}$ office visits (14.28 [3.42-59.60], $P=0.0003$ ), and Medicaid insurance (4.02 [1.15-14.07], $P=0.03$ ) (Table 3). Significant two-way interactions occurred for black race with Medicaid insurance as predictors of harmful financial impact (Table 4). That is, individuals of black race with Medicaid insurance had higher odds of harmful impact of AD OOP expenses on household finances (3.32 [1.77-6.24], $P=0.0002)$ than those of black race (1.81 [1.04-3.15], $P=0.04)$ or with Medicaid insurance alone (1.39 [1.02-1.88], $P=0.04)$.
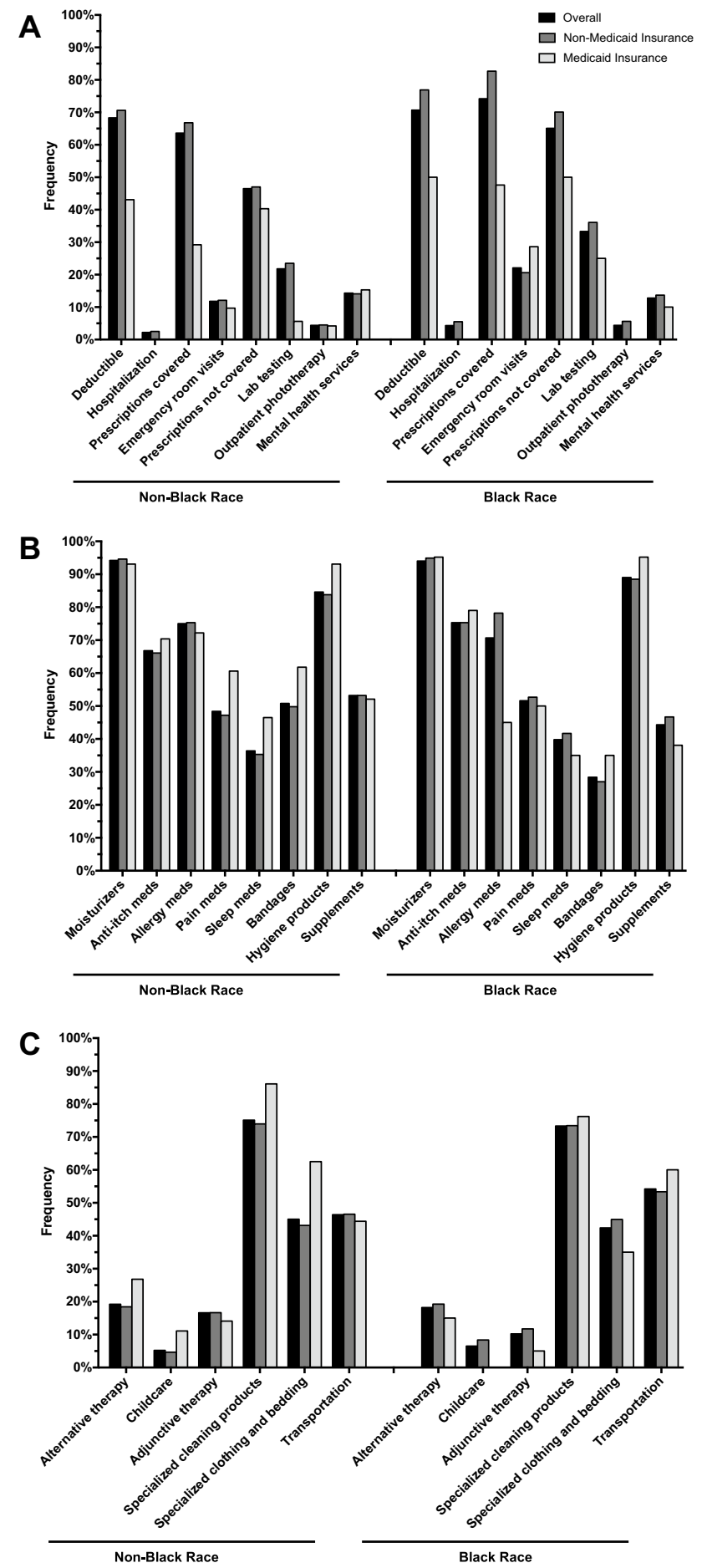

Fig. 1 Categories of OOP expense stratified by race and insurance. A OOP expenses for healthcare providers and prescriptions, B OOP expenses for non-prescription health products, C OOP expenses for complementary approaches and care coordination 
Table 2 Associations and impact of OOP expenses by race or insurance

\begin{tabular}{|c|c|c|c|c|c|c|c|}
\hline \multirow[t]{2}{*}{ Variable } & \multirow[t]{2}{*}{ Overall $(n=1018)$} & \multicolumn{3}{|l|}{ Black race } & \multicolumn{3}{|c|}{ Medicaid insurance } \\
\hline & & No $(n=861)$ & Yes $(n=102)$ & $P$ value & No $(n=861)$ & Yes $(n=93)$ & $P$ value \\
\hline \multicolumn{8}{|l|}{ Treatments } \\
\hline Step-up therapy & $442(41.0 \%)$ & $350(40.9 \%)$ & $48(47.5 \%)$ & 0.20 & $355(41.5 \%)$ & $40(43.0 \%)$ & 0.78 \\
\hline $\begin{array}{l}\text { Polypharmacy ( } \geq 3 \text { prescrip- } \\
\text { tions) }\end{array}$ & $617(57.5 \%)$ & $496(57.6 \%)$ & $63(61.8 \%)$ & 0.67 & $504(58.5 \%)$ & $51(54.8 \%)$ & 0.78 \\
\hline \multicolumn{8}{|c|}{ OOP costs for co-pays/deductibles for HCP visits in past 30 days-freq (\%) } \\
\hline$\geq \$ 100$ & $311(31.1 \%)$ & $254(30.2 \%)$ & $33(33.3 \%)$ & 0.51 & $269(32.0 \%)$ & $15(16.3 \%)$ & 0.002 \\
\hline$\geq \$ 200$ & $158(15.8 \%)$ & $129(15.3 \%)$ & $16(16.2 \%)$ & 0.83 & $138(16.4 \%)$ & $6(6.5 \%)$ & 0.01 \\
\hline \multicolumn{8}{|l|}{ OOP yearly cost-freq $(\%)$} \\
\hline$\geq \$ 1000$ & $364(41.9 \%)$ & $323(41.8 \%)$ & $39(41.9 \%)$ & & $324(41.7 \%)$ & $35(42.2 \%)$ & 0.93 \\
\hline $\begin{array}{l}\text { OOP yearly cost-median } \\
(\min , \max )\end{array}$ & $600(0,200,000)$ & $550(0,200,000)$ & $700(10,16,000)$ & 0.64 & $600(0,200,000)$ & $500(12,10,000)$ & 0.32 \\
\hline \multicolumn{8}{|c|}{ Household financial impact-freq (\%) } \\
\hline None & $61(6.3 \%)$ & $49(5.7 \%)$ & $12(11.8 \%)$ & 0.0009 & $56(6.5 \%)$ & $3(3.2 \%)$ & 0.005 \\
\hline Minimal & $281(29.1 \%)$ & $267(31.1 \%)$ & $13(12.8 \%)$ & & $262(30.5 \%)$ & $15(16.1 \%)$ & \\
\hline Moderate & $387(40.1 \%)$ & $339(39.5 \%)$ & $45(44.1 \%)$ & & $332(38.7 \%)$ & $48(51.6 \%)$ & \\
\hline Severe & $201(20.8 \%)$ & $173(20.1 \%)$ & $28(27.5 \%)$ & & $181(21.1 \%)$ & $20(21.5 \%)$ & \\
\hline Devastating & $36(3.7 \%)$ & $31(3.6 \%)$ & $4(3.9 \%)$ & & $28(3.3 \%)$ & $7(7.5 \%)$ & \\
\hline
\end{tabular}

\section{Discussion}

In this study, we found that black respondents with $\mathrm{AD}$ were significantly more likely to report OOP costs for prescription medications both covered and not covered by insurance, emergency room visits, and outpatient laboratory testing. More black individuals also reported OOP costs for office visit co-pays/deductibles, a variety of OTC medications, hygiene products, childcare, and transportation. Despite elevated OOP costs across a variety of AD healthcare categories, black respondents were more likely to have a lower household income than their non-black counterparts, and they were also more likely to report a severe or devastating financial impact on household finances. Black race itself was found to be a predictor of harmful financial impact among individuals with $\mathrm{AD}$. Taken together, these findings underscore the real-world OOP expense burden faced by black Americans with AD.

In the surveyed population, black individuals with $\mathrm{AD}$ were significantly more likely to be younger, live in an urban setting, use Medicaid insurance and have poorer disease control. In addition, predictors of harmful financial impact due to OOP expenses among blacks with AD included minimally controlled AD, systemic therapy, Medicaid insurance, and increased OOP expenses for HCP co-pays and/or deductibles. Previous studies showed that AD is more prevalent among black children in the US [18, 31, 32], and they are nearly twofold more likely to develop AD than their white counterparts, even after adjusting for sociodemographic factors [31]. Urbanization is also associated with increased risk of $\mathrm{AD}[33,34]$, with disease severity driven in part by differences in environmental factors (e.g., hygiene, pollution, exposure to infectious disease) and their interaction with skin of different races [35]. While black individuals are less likely to pursue dermatologic care overall, they are nearly threefold more likely to be diagnosed with AD during an office visit [36], and they are also more likely to have moderate-to-severe AD [19]. Those that do end up seeking outpatient $\mathrm{AD}$ care have an increased number of visits and high number of prescription medications compared to whites [37]. In a U.S population-based study, individuals with $\mathrm{AD}$ more frequently reported not being able to afford prescription medications and receive timely care [28]. Black Americans in general are more likely to be underinsured and have difficulty in obtaining medical care [38]. For those with Medicaid insurance, there are limited options for dermatologic care. A survey of dermatologists conducted by the American Academy of Dermatology reported that only $5 \%$ of practices accepted patients with Medicaid, far less than would be predicted based on the percentage of the US population receiving Medicaid at the time of the study [39]. Our findings reflect these racial and socioeconomic disparities, provide evidence for increased financial burden among blacks with $\mathrm{AD}$, and support the need for targeted strategies to address these inequities. 

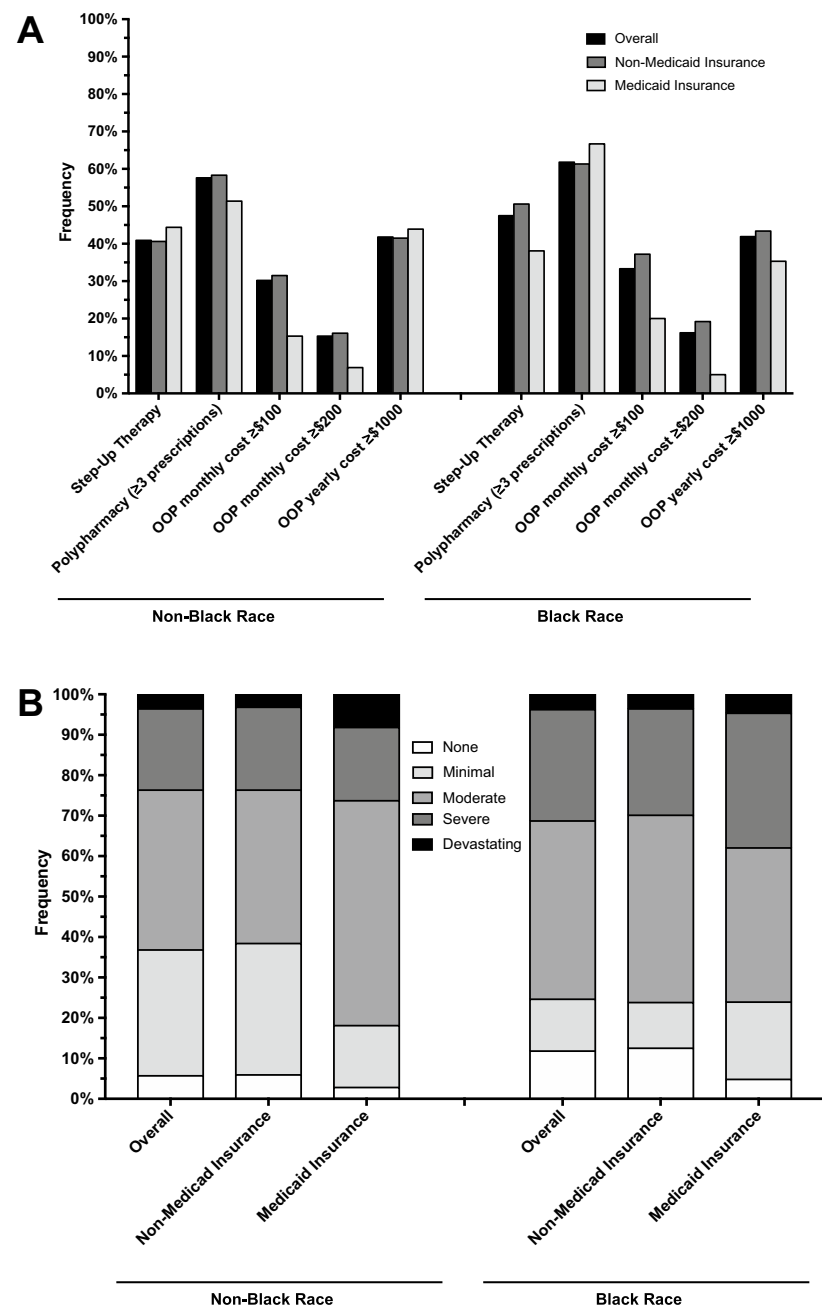

Fig. 2 Associations and impacts of OOP expenses stratified by race and insurance. A Prescription therapies and total OOP costs, B household financial impact

US adults with $\mathrm{AD}$ have high rates of emergency department (ED) and urgent care visits, and these are more common among blacks, those with lower household income, and those with prescriptions not covered by their insurance provider [26]. Frequency and costs of ED visits related to $\mathrm{AD}$ have risen over the past decade [23]. Regular use of ED care for chronic disease management is a major strain on individual and global healthcare finances and is severalfold more expensive than an outpatient office visit [40]. Black race, along with public insurance and lower household income, has also been showed to be associated with increased primary hospitalization for AD [24]. This pattern of care utilization among blacks with $\mathrm{AD}$, consisting of fewer outpatient office visits, increased prescription medications, increased ED visits, and higher risk of hospitalization, in conjunction with our findings of significantly increased
OOP expenditures in $\mathrm{ED}$, medication, and laboratory testing categories, reflects immense individual efforts to manage a high burden of disease. While no single intervention will lower OOP costs and improve access to AD care, a multifaceted strategy to optimize outpatient care could include: better training of primary care HCPs to recognize and treat mild-to-moderate $\mathrm{AD}$; a streamlined referral system with faster access to specialists such as dermatologists, especially for $\mathrm{AD}$ flares and management of any comorbid conditions; more broadly inclusive insurance coverage; and expanded use of teledermatology to better reach those who are unable to see a dermatologist.

While OOP costs were increased in several distinct categories and there was a higher proportion of Medicaid insurance use among blacks with $\mathrm{AD}$, further stratification of black race by Medicaid insurance did not reveal any significant areas of expense. Several OOP cost categories decreased among blacks with vs. without Medicaid. This likely stems from the structure of Medicaid itself, which has stringent guidelines for cost-sharing and limits OOP cost to no more than $5 \%$ of household income. Despite placing strict limits on OOP expenses and increasing overall access to care, we found that Medicaid insurance was still an independent predictor of financial impact due to OOP expenses, highlighting the financial difficulties AD patients continue to face due to limitations of Medicaid coverage. More so, black race and Medicaid insurance exhibited a two-way interaction and was associated with an even higher risk of harmful financial impact, higher than that due to either factor alone. HCPs should recognize the immense financial burden in this group of patients and proactively discuss financial impact of OOP costs alongside efficacy and safety when counseling patients. There is no "ideal" or "one-size-fits-all" treatment plan for AD. Rather, HCPs should engage in shared decision making with their AD patients-especially black patients-and create an individualized treatment plan that is practical, feasible, and financially responsible.

Study strengths include a large, racially diverse cohort of AD patients and caregivers with assessment of AD severity, control, expenses, and financial impact. The inclusion of 22 unique categories of OOP expenses allowed for accurate understanding of financial burden. The cross-sectional design of this study is an important limitation as we were unable to assess longitudinal changes in cost and impact. Though selection bias is possible given that this was an internet-based survey to the NEA membership, the respondent demographics were well distributed across races, geographic location, insurance, income, and AD severity. While self-report of costs may not be as accurate as claims analysis, direct response from 
Table 3 Predictors of financial impact by race

\begin{tabular}{|c|c|c|c|c|c|}
\hline \multicolumn{3}{|l|}{ Non-black race } & \multicolumn{3}{|l|}{ Black race } \\
\hline Variables & Adjusted odds ratio & $P$ value & Variables & Adjusted odds ratio & $P$ value \\
\hline \multicolumn{3}{|l|}{ Household income (\$) } & \multicolumn{3}{|l|}{ Age (yr) } \\
\hline$\leq 24,999$ & $1.00[\mathrm{ref}]$ & - & $\leq 2$ & $1.00[\mathrm{ref}]$ & - \\
\hline $25,000-99,999$ & $0.62[0.42-0.92]$ & 0.02 & $3-5$ & $4.88[0.27-87.88]$ & 0.28 \\
\hline$\geq 100,000$ & $0.24[0.16-0.37]$ & $<0.0001$ & $6-11$ & $2.74[0.34-22.01]$ & 0.34 \\
\hline \multicolumn{3}{|l|}{ Current AD severity } & $12-17$ & $5.87[0.47-74.02]$ & 0.17 \\
\hline Clear & $1.00[\mathrm{ref}]$ & - & $18-25$ & $0.22[0.03-1.53]$ & 0.13 \\
\hline Mild & $0.96[0.39-2.34]$ & 0.93 & $26-35$ & $0.27[0.03-2.53]$ & 0.25 \\
\hline Moderate & $1.59[0.67-3.77]$ & 0.30 & $36-50$ & $0.48[0.07-3.52]$ & 0.47 \\
\hline Severe & $3.02[1.24-7.36]$ & 0.02 & $51-64$ & $2.52[0.348-18.29]$ & 0.36 \\
\hline \multicolumn{3}{|l|}{ Asthma } & $\geq 65$ & $0.05[0.01-0.46]$ & 0.01 \\
\hline No & $1.00[\mathrm{ref}]$ & - & \multicolumn{3}{|l|}{ Current AD control } \\
\hline Yes & $1.41[1.05-1.89]$ & 0.02 & Very well controlled & $1.00[\mathrm{ref}]$ & - \\
\hline \multicolumn{3}{|l|}{$\mathrm{HCP}$ visits in past year } & Moderately well controlled & $3.18[0.43-23.71]$ & 0.26 \\
\hline 0 & $1.00[\mathrm{ref}]$ & - & Somewhat controlled & $2.50[0.38-16.35]$ & 0.34 \\
\hline $1-2$ & $1.40[0.84-2.33]$ & 0.20 & Minimally controlled & $13.88[1.63-117.96]$ & 0.02 \\
\hline $3-4$ & $1.68[0.97-2.91]$ & 0.06 & \multicolumn{3}{|l|}{ Anxiety and/or depression } \\
\hline$\geq 5$ & $2.94[1.64-5.26]$ & 0.0003 & No & $1.00[\mathrm{ref}]$ & - \\
\hline \multicolumn{3}{|c|}{$\begin{array}{l}\text { OOP co-pays and/or deductibles for healthcare provider office visits in } \\
\text { past } 30 \text { days }\end{array}$} & Yes & $4.34[1.37-13.70]$ & 0.01 \\
\hline$\leq \$ 200$ & $1.00[\mathrm{ref}]$ & - & \multicolumn{3}{|l|}{ Step-up therapy } \\
\hline$>\$ 200$ & $1.95[1.28-2.99]$ & 0.002 & No & $1.00[\mathrm{ref}]$ & - \\
\hline \multicolumn{3}{|l|}{ Annual OOP expenses } & Yes & $4.34[1.63-11.54]$ & 0.003 \\
\hline$\leq \$ 1000$ & $1.00[\mathrm{ref}]$ & - & \multicolumn{3}{|l|}{ Medicaid insurance } \\
\hline \multirow[t]{5}{*}{$>\$ 1000$} & $4.87[3.46-6.86]$ & $<0.0001$ & No & 1.00 [ref] & - \\
\hline & & & Yes & $4.02[1.15-14.07]$ & 0.03 \\
\hline & & & \multicolumn{3}{|c|}{$\begin{array}{l}\text { OOP co-pays and/or deductibles for healthcare provider office visits } \\
\text { in past } 30 \text { days }\end{array}$} \\
\hline & & & $\leq \$ 200$ & $1.00[\mathrm{ref}]$ & - \\
\hline & & & $>\$ 200$ & $14.28[3.42-59.60]$ & 0.0003 \\
\hline
\end{tabular}

Table 4 Effect of interaction between black race and medicaid insurance as predictors of household financial impact due to OOP expenses

\begin{tabular}{llllll}
\hline Black race & $\begin{array}{l}\text { Medicaid } \\
\text { insurance }\end{array}$ & Crude OR [95\% CI] & $P$ value & Adjusted OR [95\% CI] & $P$ value \\
\hline No & No & $1.00[$ ref] & & $1.00[$ ref] & \\
Yes & No & $1.74[1.04-2.93]$ & 0.04 & $1.81[1.04-3.15]$ & 0.04 \\
No & Yes & $1.34[1.01-1.79]$ & 0.04 & $1.39[1.02-1.88]$ & 0.04 \\
Yes & Yes & $2.11[1.17-3.82]$ & 0.01 & $3.32[1.77-6.24]$ & 0.0002 \\
\hline
\end{tabular}

Adjusted model includes gender, geographic settings, measures of disease activity (severity, control, flares), number of healthcare provider visits, total number of prescription medications, step-up therapy, comorbidities (allergic rhinitis, asthma, skin infections, anxiety and/or depression), and monthly OOP expenses as covariates patients and caregivers allows for more complete assessment of disease state and household finances. Additional studies are needed to confirm these findings and better understand OOP expenses across other races and socioeconomic groups.
In conclusion, among individuals with $\mathrm{AD}$, black race is associated with increased OOP expenses in a variety of unique healthcare categories and significant household financial impact. Additional studies are needed to better understand unique OOP financial considerations among 
black individuals and develop targeted approaches to reduce both the financial and overall burden of AD.

Supplementary Information The online version contains supplementary material available at https://doi.org/10.1007/s00403-021-02282-3.

Author contributions WSB had full access to all the data in the study and takes responsibility for the integrity of the data and accuracy of the data analysis. Study concept and design: WSB, IJT, JIS. Acquisition of data: WSB, IJT. Analysis and interpretation of data: RC, WSB, IJT, JIS. Drafting of the manuscript: RC, WSB, IJT, JIS. Critical revision of the manuscript for important intellectual content: RC, WSB, IJT, JIS. Statistical analysis: RC, WSB, IJT, JIS.

Funding National Eczema Association.

\section{Declarations}

Conflict of interest Raj Chovatiya reports personal fees from Abbvie, Regeneron, and Sanofi-Genzyme. Jonathan Silverberg reports personal fees from Abbvie, Anaptysbio, Asana, EliLilly, Galderma, GlaxoSmithKline, Kiniksa, Leo, Menlo, Pfizer, Realm, RegeneronSanofi, and Roivant, and grants from GlaxoSmithKline, Regeneron, Sanofi-Genzyme, and Galderma. Wendy Begolka and Isabelle Thibau declare no competing interests.

Open Access This article is licensed under a Creative Commons Attribution 4.0 International License, which permits use, sharing, adaptation, distribution and reproduction in any medium or format, as long as you give appropriate credit to the original author(s) and the source, provide a link to the Creative Commons licence, and indicate if changes were made. The images or other third party material in this article are included in the article's Creative Commons licence, unless indicated otherwise in a credit line to the material. If material is not included in the article's Creative Commons licence and your intended use is not permitted by statutory regulation or exceeds the permitted use, you will need to obtain permission directly from the copyright holder. To view a copy of this licence, visit http://creativecommons.org/licenses/by/4.0/.

\section{References}

1. Fuxench ZCC, Block JK, Boguniewicz M, Boyle J, Fonacier L, Gelfand JM et al (2019) Atopic Dermatitis in America Study: a cross-sectional study examining the prevalence and disease burden of atopic dermatitis in the US adult population. J Invest Dermatol 139(3):583-590. https://doi.org/10.1016/j.jid.2018.08. 028

2. Silverberg JI, Gelfand JM, Margolis DJ, Boguniewicz M, Fonacier L, Grayson MH et al (2018) Patient burden and quality of life in atopic dermatitis in US adults: a population-based cross-sectional study. Ann Allergy Asthma Immunol 121(3):340-347. https://doi. org/10.1016/j.anai.2018.07.006

3. Hua T, Silverberg JI (2018) Atopic dermatitis in US adults: epidemiology, association with marital status, and atopy. Ann Allergy Asthma Immunol 121(5):622-624. https://doi.org/10.1016/j.anai. 2018.07.019

4. Silverberg JI, Margolis DJ, Boguniewicz M, Fonacier L, Grayson MH, Ong PY et al (2019) Distribution of atopic dermatitis lesions in United States adults. J Eur Acad Dermatol Venereol JEADV 33(7):1341-1348. https://doi.org/10.1111/jdv.15574

5. Vakharia PP, Chopra R, Sacotte R, Patel KR, Singam V, Patel N et al (2017) Burden of skin pain in atopic dermatitis. Ann Allergy
Asthma Immunol 119(6):548-52.e3. https://doi.org/10.1016/j. anai.2017.09.076

6. Silverberg JI, Gelfand JM, Margolis DJ, Boguniewicz M, Fonacier L, Grayson MH et al (2019) Symptoms and diagnosis of anxiety and depression in atopic dermatitis in U.S. adults. Br J Dermatol 119:548-52 e3. https://doi.org/10.1111/bjd.17683

7. Silverberg JI, Gelfand JM, Margolis DJ, Boguniewicz M, Fonacier $\mathrm{L}$, Grayson MH et al (2018) Association of atopic dermatitis with allergic, autoimmune, and cardiovascular comorbidities in US adults. Ann Allergy Asthma Immunol 121(5):604-12.e3. https:// doi.org/10.1016/j.anai.2018.07.042

8. Silverberg JI (2019) Comorbidities and the impact of atopic dermatitis. Ann Allergy Asthma Immunol 123(2):144-151. https:// doi.org/10.1016/j.anai.2019.04.020

9. Hong MR, Lei D, Yousaf M, Chavda R, Gabriel S, Janmohamed SR et al (2020) A real-world study of the longitudinal course of adult atopic dermatitis severity in clinical practice. Ann Allergy Asthma Immunol 125(6):686-92.e3. https://doi.org/10.1016/j. anai.2020.07.005

10. Kim JP, Chao LX, Simpson EL, Silverberg JI (2016) Persistence of atopic dermatitis (AD): a systematic review and meta-analysis. J Am Acad Dermatol 75(4):681-7.e11. https://doi.org/10.1016/j. jaad.2016.05.028

11. Silverberg JI, Gelfand JM, Margolis DJ, Boguniewicz M, Fonacier L, Grayson MH et al (2019) Health utility scores of atopic dermatitis in US adults. J Allergy Clin Immunol Pract 7(4):1246-52.e1. https://doi.org/10.1016/j.jaip.2018.11.043

12. Haeck IM, Berge OT, Velsen SGAV, Bruin-Weller MSD, Bruijnzeel-Koomen CAFM, Knol MJ (2012) Moderate correlation between quality of life and disease activity in adult patients with atopic dermatitis. J Eur Acad Dermatol Venereol JEADV. 26(2):236-241. https://doi.org/10.1111/j.1468-3083.2011.04043.x

13. Silverberg JI (2015) Racial and ethnic disparities in atopic dermatitis. Curr Dermatol Rep 4(1):44-48. https://doi.org/10.1007/ s13671-014-0097-7

14. Kim Y, Blomberg M, Rifas-Shiman SL, Camargo CA, Gold DR, Thyssen JP et al (2019) Racial/ethnic differences in incidence and persistence of childhood atopic dermatitis. J Invest Dermatol 139(4):827-834. https://doi.org/10.1016/j.jid.2018.10.029

15. Brunner PM, Guttman-Yassky E (2019) Racial differences in atopic dermatitis. Ann Allergy Asthma Immunol 122(5):449-455. https://doi.org/10.1016/j.anai.2018.11.015

16. Silverberg JI, Paller AS (2015) Association between eczema and stature in 9 US population-based studies. JAMA Dermatol 151(4):401-409. https://doi.org/10.1001/jamadermatol.2014. 3432

17. Silverberg JI, Simpson EL (2014) Association between obesity and eczema prevalence, severity and poorer health in US adolescents. Dermatitis Contact Atopic Occup Drug 25(4):172-181. https://doi.org/10.1097/der.0000000000000047

18. Silverberg JI, Hanifin J, Simpson EL (2013) Climatic factors are associated with childhood eczema prevalence in the United States. J Invest Dermatol 133(7):1752-1759. https://doi.org/10.1038/jid. 2013.19

19. Silverberg JI, Simpson EL (2014) Associations of childhood eczema severity: a US population-based study. Dermatitis Contact Atopic Occup Drug 25(3):107-114. https://doi.org/10.1097/der. 0000000000000034

20. Havstad S, Johnson CC, Kim H, Levin AM, Zoratti EM, Joseph CLM et al (2014) Atopic phenotypes identified with latent class analyses at age 2 years. J Allergy Clin Immun 134(3):722-7.e2. https://doi.org/10.1016/j.jaci.2014.01.022PMID-24636082

21. Wan J, Margolis DJ, Mitra N, Hoffstad OJ, Takeshita J (2019) Racial and ethnic differences in atopic dermatitis-related school absences among US children. JAMA Dermatol 155(8):973-975. https://doi.org/10.1001/jamadermatol.2019.0597PMID-31116350 
22. Drucker AM, Qureshi AA, Amand C, Villeneuve S, Gadkari A, Chao J et al (2018) Health care resource utilization and costs among adults with atopic dermatitis in the United States: a claimsbased analysis. J Allergy Clin Immunol Pract 6(4):1342-1348. https://doi.org/10.1016/j.jaip.2017.10.024

23. Kwa L, Silverberg JI (2018) Financial burden of emergency department visits for atopic dermatitis in the United States. J Am Acad Dermatol 79(3):443-447. https://doi.org/10.1016/j.jaad. 2018.05.025

24. Narla S, Hsu DY, Thyssen JP, Silverberg JI (2018) Predictors of hospitalization, length of stay, and costs of care among adult and pediatric inpatients with atopic dermatitis in the United States. Dermatitis Contact Atopic Occupational Drug 29(1):22-31. https://doi.org/10.1097/der.0000000000000323

25. Hua T, Silverberg JI (2019) Atopic dermatitis is associated with increased hospitalization in US children. J Am Acad Dermatol 81(3):862-865. https://doi.org/10.1016/j.jaad.2019.05.019

26. Silverberg JI, Gelfand JM, Margolis DJ, Boguniewicz M, Fonacier L, Grayson MH et al (2019) Atopic dermatitis in US adults: from population to health care utilization. J Allergy Clin Immunol Pract 7(5):1524-32.e2. https://doi.org/10.1016/j.jaip.2019.01.005

27. Singh P, Silverberg JI (2019) Outpatient utilization patterns for atopic dermatitis in the United States. J Am Acad Dermatol. https://doi.org/10.1016/j.jaad.2019.03.021

28. Silverberg JI (2015) Health care utilization, patient costs, and access to care in US adults with eczema: a population-based study. JAMA Dermatol 151(7):743-752. https://doi.org/10.1001/jamad ermatol.2014.5432

29. Whiteley J, Emir B, Seitzman R, Makinson G (2016) The burden of atopic dermatitis in US adults: results from the 2013 National Health and Wellness Survey. Curr Med Res Opin 32(10):16451651. https://doi.org/10.1080/03007995.2016.1195733

30. Begolka WS, Chovatiya R, Thibau IJ, Silverberg JI (2020) Financial burden of atopic dermatitis out-of-pocket health care expenses in the United States. Dermatitis Contact Atopic Occup Drug. https://doi.org/10.1097/der.0000000000000715

31. Shaw TE, Currie GP, Koudelka CW, Simpson EL (2011) Eczema prevalence in the United States: data from the 2003 National Survey of Children's Health. J Invest Dermatol 131(1):67-73. https:// doi.org/10.1038/jid.2010.251

32. Fu T, Keiser E, Linos E, Rotatori RM, Sainani K, Lingala B et al (2014) Eczema and sensitization to common allergens in the United States: a multiethnic, population-based study. Pediatr Dermatol 31(1):21-26. https://doi.org/10.1111/pde.12237

33. Lusignan S, Alexander H, Broderick C, Dennis J, McGovern A, Feeney $\mathrm{C}$ et al (2021) The epidemiology of eczema in children and adults in England: a population-based study using primary care data. Clin Exp Allergy 51(3):471-482. https://doi.org/10.1111/ cea. 13784

34. Wang X, Zhuang Y, Chen Y, Wang H, Wang X (2021) Prevalence of adult eczema, hay fever, and asthma, and associated risk factors: a population-based study in the northern Grassland of China. Allergy Asthma Clin Immunol 17(1):27. https://doi.org/10.1186/ s13223-021-00532-7

35. Merriman JA, Mueller EA, Cahill MP, Beck LA, Paller AS, Hanifin JM et al (2016) Temporal and racial differences associated with atopic dermatitis Staphylococcus aureus and encoded virulence factors. Msphere 1(6):e00295-e316. https://doi.org/10.1128/ msphere.00295-16

36. Janumpally SR, Feldman SR, Gupta AK, Fleischer AB (2002) In the United States, Blacks and Asian/Pacific Islanders are more likely than whites to seek medical care for atopic dermatitis. Arch Dermatol 138(5):634-637. https://doi.org/10.1001/archderm. 138.5.634

37. Fischer AH, Shin DB, Margolis DJ, Takeshita J (2017) Racial and ethnic differences in health care utilization for childhood eczema: An analysis of the 2001-2013 Medical Expenditure Panel Surveys. J Am Acad Dermatol 77(6):1060-1067. https://doi.org/10. 1016/j.jaad.2017.08.035

38. Neighbors HW, Jackson JS (1987) Barriers to medical care among adult blacks: what happens to the uninsured? J Natl Med Assoc 79(5):489-493

39. Resneck JS, Isenstein A, Kimball AB (2006) Few Medicaid and uninsured patients are accessing dermatologists. J Am Acad Dermatol 55(6):1084-1088. https://doi.org/10.1016/j.jaad.2006.07. 012

40. Baker LC, Baker LS (2017) Excess Cost of Emergency Department Visits for Nonurgent Care. Health Affair 13(5):162-171. https://doi.org/10.1377/hlthaff.13.5.162

Publisher's Note Springer Nature remains neutral with regard to jurisdictional claims in published maps and institutional affiliations. 